\title{
The Transverse Rupture Strength in Ti-6Al-4V Alloy Manufactured by Selective Laser Melting
}

\author{
Pang-Hsin Lai, Jhewn-Kuang Chen, and Ming-Wei Wu ${ }^{a}$ \\ Department of Materials and Mineral Resources Engineering, National Taipei University of Technology, Taipei 10608, Taiwan, ROC
}

\begin{abstract}
The objective of this study was to investigate the transverse rupture strength and apparent hardness of selective laser melted Ti-6Al-4V alloys manufactured in the vertical (V) and horizontal (H) directions. The microstructure and the distribution of alloy elements were examined by optical microscope and electron probe microanalysis, respectively. The results show that the columnar $\alpha^{\prime}$ grains are formed along the building direction, and the elemental distributions of $\mathrm{Ti}, \mathrm{Al}$, and $\mathrm{V}$ are homogeneous in the alloy. The building direction does not sufficiently affect the density and apparent hardness. However, the transverse rupture strengths (TRS) are obviously dominated by the building directions investigated in this study. The TRS of an $\mathrm{H}$ specimen is significantly superior to that of a $\mathrm{V}$ specimen by $48 \%$. This phenomenon can be mainly attributed to the presence of disc-shaped pores.
\end{abstract}

\section{Introduction}

Ti-6Al-4V alloys are widely used in industry due to their excellent strength-to-weight ratio, mechanical properties, anti-corrosion, and biocompatibility. Compared with conventional processes, selective laser melting (SLM) is a versatile method of producing Ti alloys with complicated shapes $[1,2]$. Unfortunately, the manufacture of metallic material by the SLM process has several disadvantages, such as high-priced raw materials, expensive SLM machines, and low productivity.

The influences of various SLM parameters, including laser power, scan speed, and hatching distance, on the SLM Ti-6Al-4V alloys have been studied extensively [1, 3]. SLM Ti-6Al-4V alloys exhibit a high anisotropy of properties in the final manufactured parts [4-6]. Several studies have indicated that the building direction may affect the tensile and fatigue properties of these alloys [412]. However, the anisotropy in the bending and impact properties has rarely been examined. This study investigated the correlation between the building direction and the TRS of SLM Ti-6Al-4V alloys. To understand the fracture features, the bending fracture surfaces were also examined under SEM.

\section{Experimental procedures}

A plasma-atomized Ti-6Al-4V powder, as shown in Fig. 1, was used as the raw material in this study. The raw particles were spherical, and the median particle size (D50) was $33 \mu \mathrm{m}$. TRS specimens with dimensions of $31.8 \times 12.7 \times 6.35 \mathrm{~mm} 3$ were produced in a SLM machine. The powder was repeatedly packed in the powder bed and was then melted by a scanning laser beam. The laser power and scan speed were chosen to minimize the number of micro-porosity. The hatching distance and later thickness were $120 \mu \mathrm{m}$ and $50 \mu \mathrm{m}$, respectively. To investigate the relationship between the building direction and the TRS, the SLM specimens were built in the vertical and horizontal directions. Fig. 2 shows that the long edges of the vertical and horizontal specimens were parallel and perpendicular to the building direction ( $\mathrm{z}$ axis), respectively. The vertical and horizontal specimens were designated as $\mathrm{V}$ and $\mathrm{H}$, respectively.

\footnotetext{
${ }^{a}$ Corresponding author: mwwu@ntut.edu.tw
} 


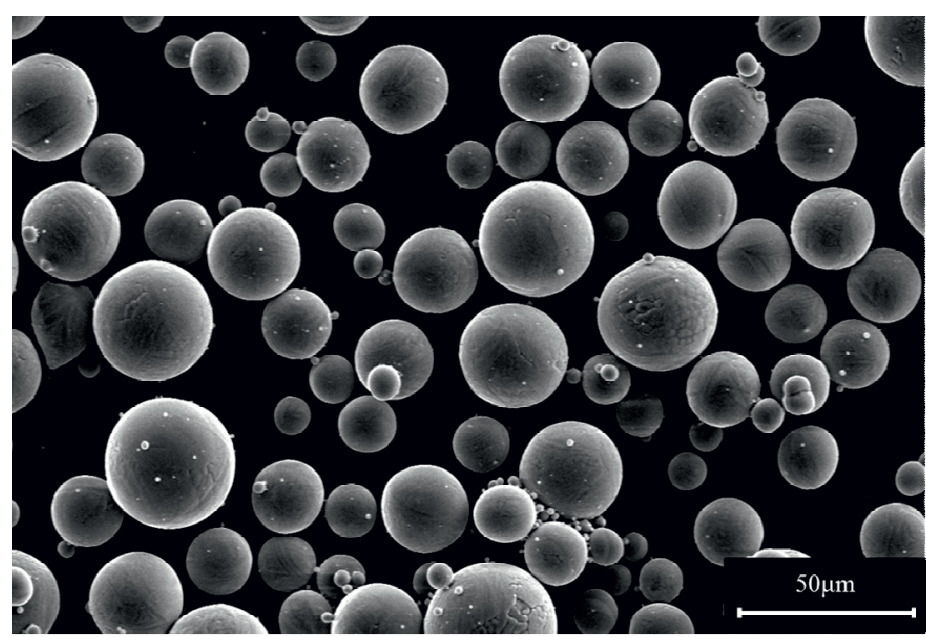

Figure 1. The appearance of Ti-6Al-4V powder used in this study.

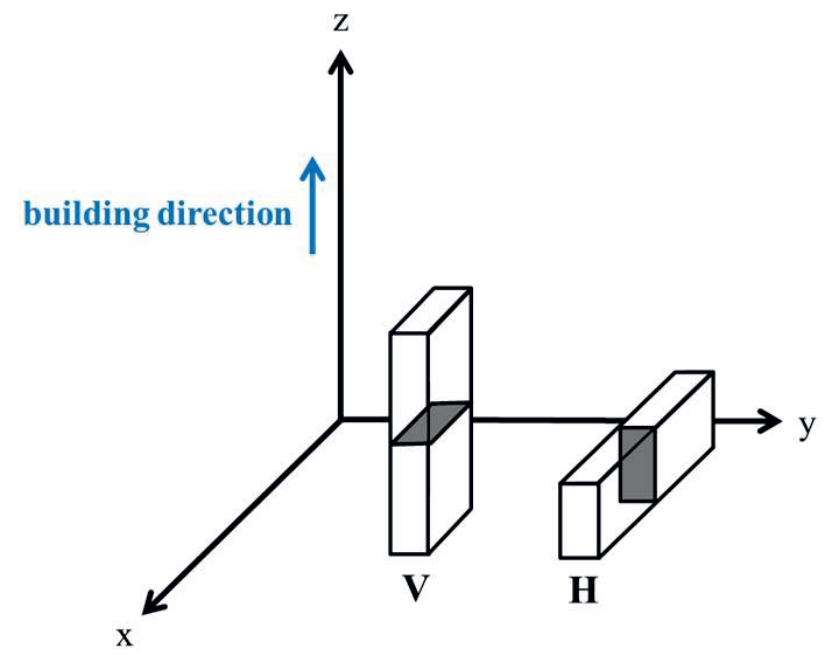

Figure 2. The schematic of SLM Ti-6Al-4V alloys manufactured by vertical and horizontal directions.

To observe the cross-section microstructure, the two types of SLM specimens were sampled, ground, polished, and etched with a mixed solution of $90 \%$ distilled water, $5 \% \mathrm{HF}$, and $5 \% \mathrm{HNO}$. The cross-sections of the two types of SLM specimens observed in this study are marked in grey in Fig. 2. After the sample preparation, the samples were observed under an optical microscope. An x-ray diffractometer (XRD, D2, Bruker, Karlsruhe, Germany) and an electron probe micro-analyzer (EPMA, JXA-8200SX, JEOL, Tokyo, Japan) were used to clarify the crystal structure and elemental distributions, respectively.

The sintered densities were evaluated using the Archimedes' method. The TRS specimens were tested using a material testing machine (HT-9510, Hung Ta Instrument Co., Taiwan, ROC). The bending fracture surfaces were further examined under a scanning electron microscope (JSM-6510, JEOL, Tokyo, Japan). Apparent hardness on the HRC scale was also measured.

\section{Results and Discussion}

Fig. 3 shows the cross-section microstructures of Ti$6 \mathrm{Al}-4 \mathrm{~V}$ alloy produced in the two directions and indicates the anisotropy in the microstructure. The $\mathrm{V}$ and $\mathrm{H}$ specimens exhibited equiaxed grains and long columnar grains, respectively. The average sizes of equiaxed grains, shown in Fig. 3(a), were approximately equal to the width of the columnar grains, shown in Fig. 3(b), indicating that the columnar grains were arranged along the building direction ( $\mathrm{z}$ axis), irrespective of the building orientation. This anisotropy in the microstructure can be attributed the heat flow along the building direction during SLM [1]. XRD results showed that the crystal structures of the $\mathrm{V}$ and $\mathrm{H}$ specimens were fully $\alpha^{\prime}$ martensite phases, due to the rapid cooling rates after SLM. The distributions of $\mathrm{Ti}, \mathrm{Al}$, and $\mathrm{V}$ atoms in the $\mathrm{H}$ specimen were analyzed by elemental mapping using EPMA, as shown in Fig. 4. The results showed that Ti, Al, and $\mathrm{V}$ were distributed homogeneously throughout the SLM Ti-6Al-4V alloy, and no apparent segregation was observed. The elemental distributions in the $\mathrm{V}$ specimen were identical to those in the $\mathrm{H}$ specimen and did not be shown in this study. 


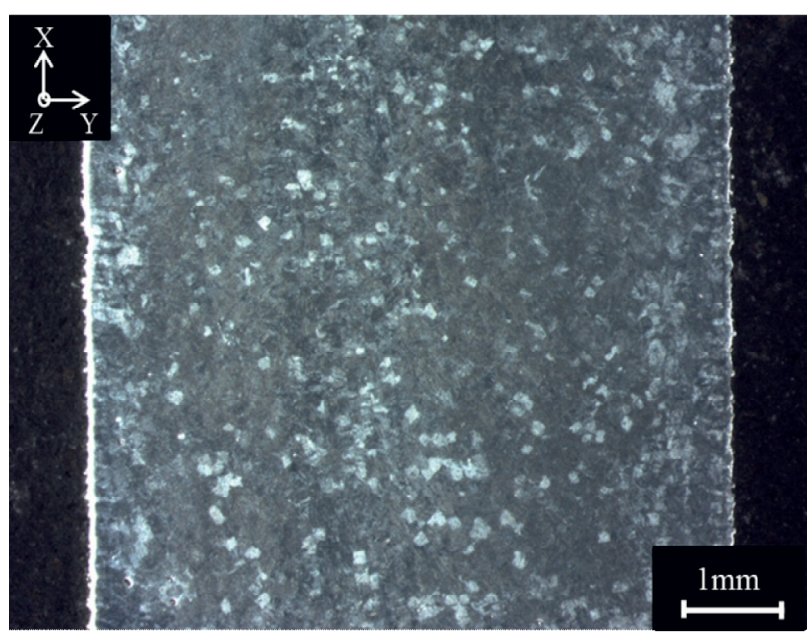

(a)

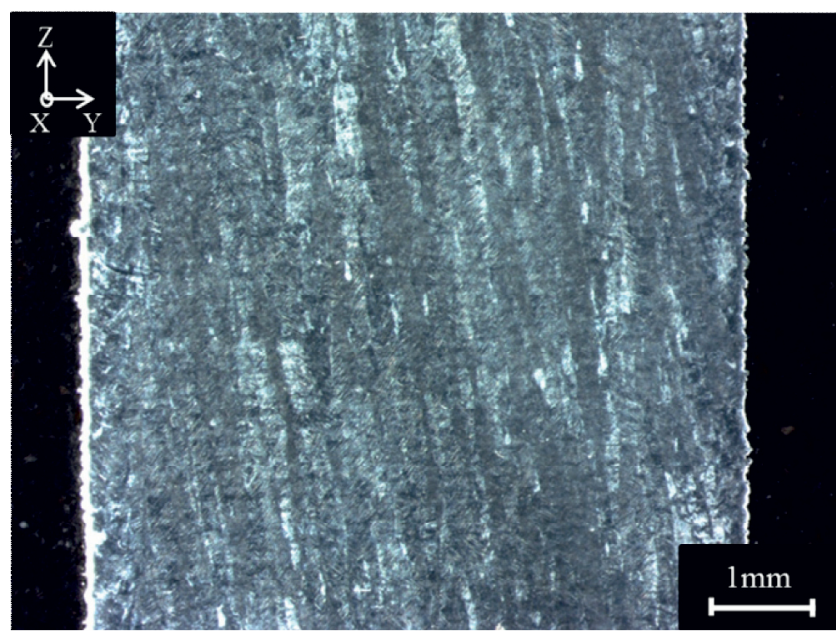

(b)

Figure 3. The microstructures of (a) V and (b) H specimens.
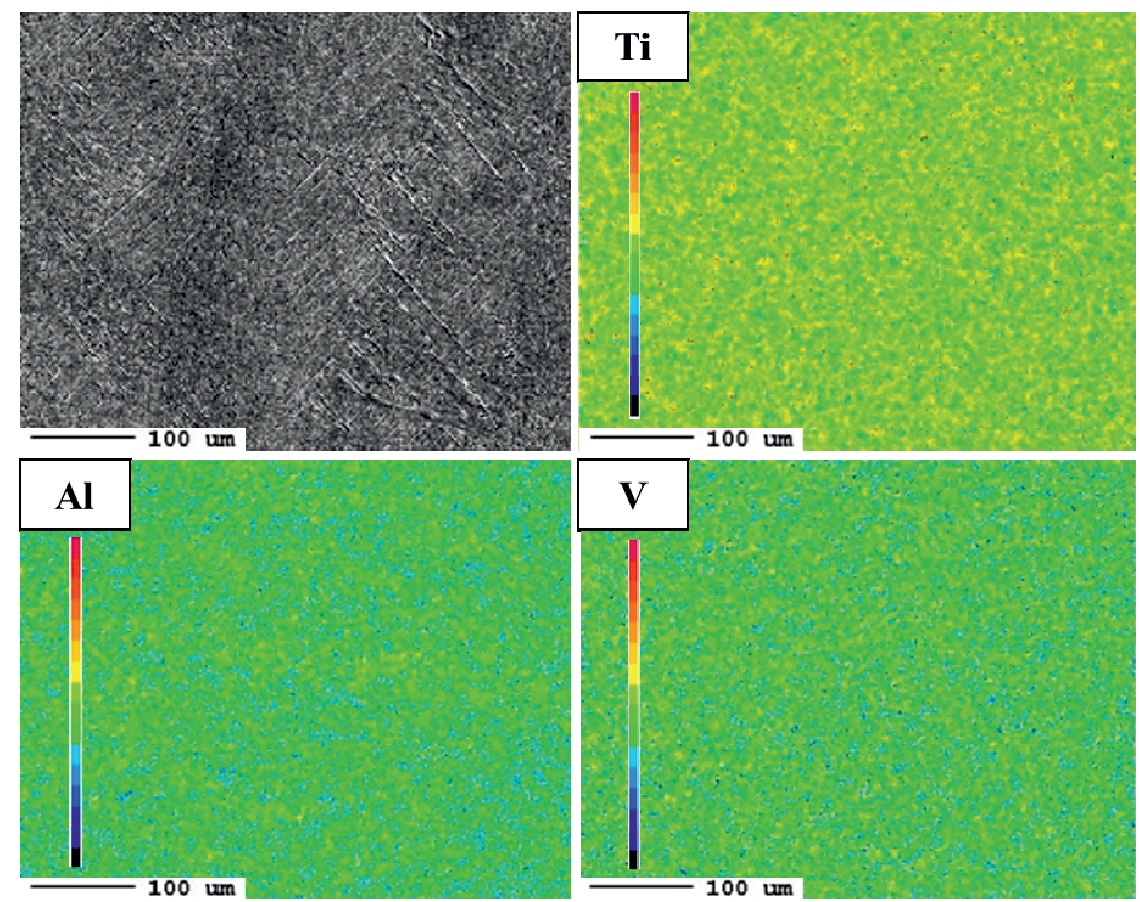

Figure 4. The distributions of alloying elements in the H specimen.

Table 1 shows the densities and mechanical properties of the SLM specimens. The densities of SLM Ti-6Al-4V alloys were higher than $4.35 \mathrm{~g} / \mathrm{cm} 3$ because the Ti-6Al$4 \mathrm{~V}$ powders in the powder bed were melted during SLM. The apparent hardness of $\mathrm{V}$ and $\mathrm{H}$ specimens were 41.5 HRC and 40.9 HRC, respectively. These findings demonstrate that the building direction did not obviously affect the densification and apparent hardness of SLM Ti-
6Al-4V alloys, as shown in Table 1. Nevertheless, the TRS of the $\mathrm{V}$ and $\mathrm{H}$ specimens were $1487 \mathrm{MPa}$ and 2198 $\mathrm{MPa}$, respectively, indicating that the building direction significantly affects the TRS. This difference could not be attributed to the columnar $\alpha^{\prime}$ grains because the bending stress axis was perpendicular to the columnar $\alpha^{\prime}$ grain in the two specimens. 
Table 1. The densities and mechanical properties of SLM Ti-6Al-4V alloys.

\begin{tabular}{cccc}
\hline & & & \\
Condition & $\begin{array}{c}\text { Density } \\
\left(\mathrm{g} / \mathrm{cm}^{3}\right)\end{array}$ & $\begin{array}{c}\text { Apparent Hardness } \\
(\text { HRC })\end{array}$ & $\begin{array}{c}\text { TRS } \\
(\mathrm{MPa})\end{array}$ \\
\hline $\mathrm{V}$ & 4.40 & 41.5 & 1487 \\
\hline $\mathrm{H}$ & 4.36 & 40.9 & 2198
\end{tabular}

To illustrate the difference in TRS between the two specimens, the bending fracture surfaces are presented in Fig. 5. The results showed ductile fractures and minor pores in the fracture surfaces, irrespective of the building direction. However, the pores in the fracture surfaces of the $\mathrm{V}$ and $\mathrm{H}$ specimens were nearly spherical and linear, respectively. Fig. 6 clearly indicates that these pores were disc-shaped, and the appearances of pores in the fracture surfaces of the $\mathrm{V}$ and $\mathrm{H}$ specimens were different. Due to the pore geometry, the ratios of porosity in the fracture surfaces of the $\mathrm{V}$ specimens were obviously higher those of $\mathrm{H}$ specimens, as shown in Fig. 5. Thus, the pores in the $\mathrm{V}$ specimens sufficiently decreased the load-bearing cross-section and impaired the TRS. In conclusion, the anisotropy in the TRS of as-built SLM Ti-6Al-4V alloy could be mainly attributed to the pore geometry and its distribution. To further understand the effects of the discshaped building defects and the columnar $\alpha^{\prime}$ grains on the various mechanical properties of as-built SLM Ti-6Al-4V alloy, the anisotropy in the tensile and impact properties will also be investigated in the future.

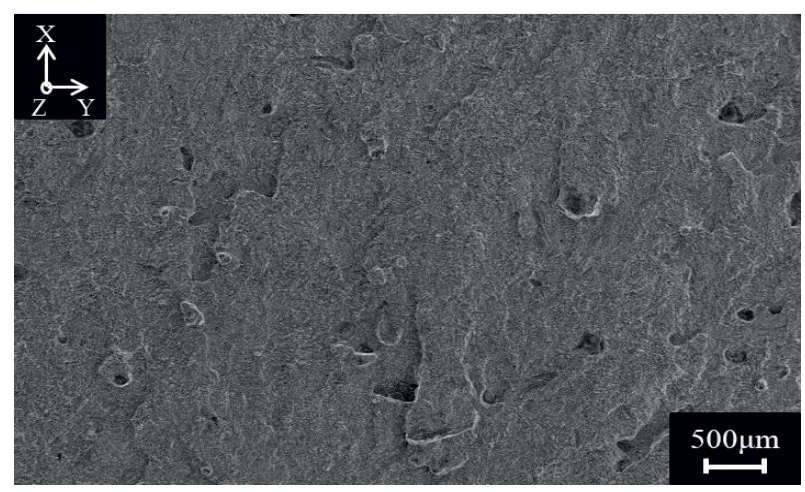

(a)

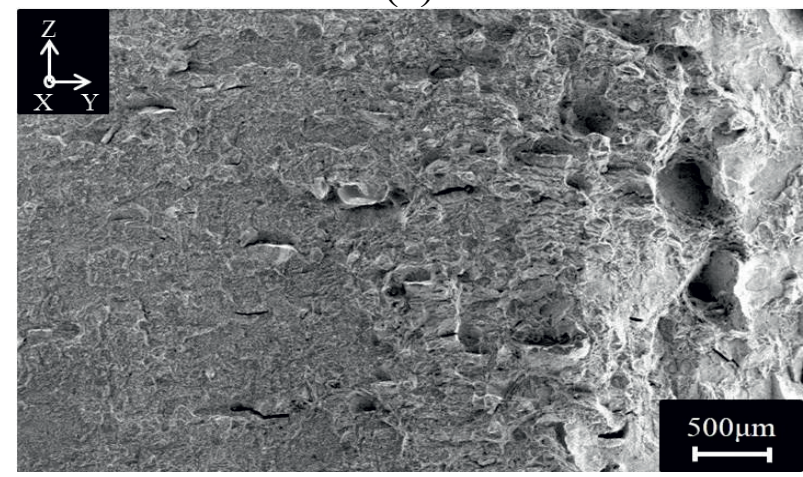

(b)

Figure 5. The bending fracture surfaces of (a) V and (b) $\mathrm{H}$ specimens.

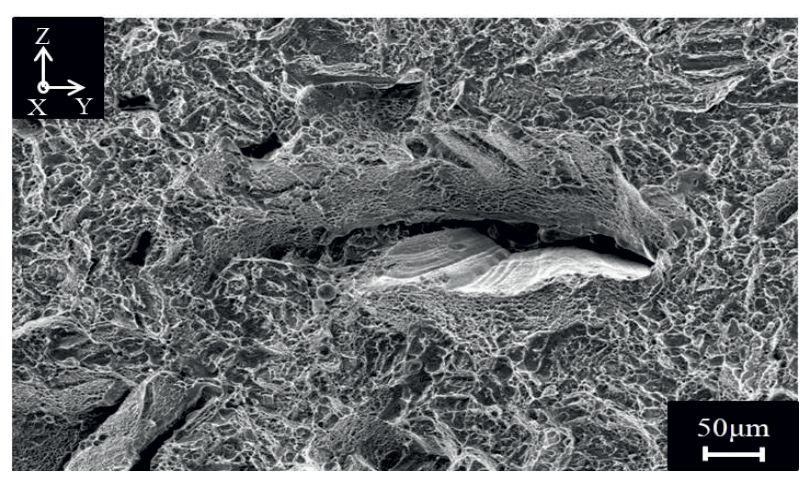

Figure 6. Morphology of a large building defect in the bending fracture surface of an $\mathrm{H}$ specimen.

\section{Summary}

The microstructure of SLM Ti-6Al-4V alloy is fully $\alpha^{\prime}$-martensite phase. Columnar $\alpha^{\prime}$ grains are arranged along the building direction ( $\mathrm{z}$ axis). The distributions of $\mathrm{Ti}, \mathrm{Al}$, and $\mathrm{V}$ atoms are homogeneous, as examined by EPMA.

The densities and apparent hardnesses of SLM Ti6Al-4V alloys were higher than $4.35 \mathrm{~g} / \mathrm{cm} 3$ and HRC 40, respectively. The building direction does not apparently affect the densification and apparent hardness.

The TRS of an $\mathrm{H}$ specimen is significantly higher than that of a V specimen by $48 \%$. The columnar $\alpha^{\prime}$ grains do not play an obvious role in the TRS. This phenomenon could be due mainly to the presence of discshaped pores.

\section{Acknowledgement}

The authors thank the Ministry of Science and Technology of the Republic of China for funding and support under contract number MOST 103-2218-E-027014.

\section{References}

1. L. Thijs, F. Verhaeghe, T. Craeghs, J.V. Humbeeck, and J.P. Kruth, Acta Mater. 58, 3303(2010)

2. R. Wauthle, B. Vrancken, B. Beynaerts, K. Jorissen, J. Schrooten, J.P. Kruth, and J.V. Humbeeck, Additive Manufacturing, 5, 77(2015)

3. H. Attar, M. Calin, L.C. Zhang, S. Scudino, and J. Eckert, Mater. Sci. Eng. A 593, 170(2014)

4. E. Chlebus, B. Kuźnicka, T. Kurzynowski, and B. Dybała, Mater. Charact. 62, 488(2011) 
5. M. Simonelli, Y.Y. Tse, and C. Tuck, Mater. Sci. Eng. A 616, 1(2014)

6. T. Brynk, B. Romelczyk, Z. Pakiela, T. Kurzynowski, and E. Chlebus, Key Eng. Mater. 627, 305(2015)

7. T. Vilaro, C. Colin, and J.D. Bartout, Metall. Mater. Trans. A 42, 3190(2011)

8. C. Qiu, N.J.E. Adkins, and M.M. Attallah, Mater. Sci. Eng. A 578, 230(2013)

9. A. Mertens, S. Reginster, H. Paydas, Q. Contrepois,
T. Dormal, O. Lemaire, and J. Lecomte-Beckers, Powder Metall. 57, 184(2014)

10. P. Edwards and M. Ramulu, Mater. Sci. Eng. A 598, 32, 7(2014)

11. B. Ahuja, A. Schaub, M. Karg, M. Lechner, M. Merklein, and M. Schmidt, Phys. Procedia 56, 90(2014)

12. V. Cain, L. Thijs, J.V. Humbeeck, B.V. Hooreweder, and R. Knutsen, Additive Manufacturing, 5, 68(2015) 